\title{
Pelaksanaan Budaya Keselamatan Pasien pada Masa Pandemi Covid-19 di Rumah Sakit Umum Daerah Bima
}

\author{
Muhtar $^{1(\mathrm{CA})}$, Aniharyati ${ }^{2}$, Ahmad $^{3}$ \\ 1(CA)Jurusan Keperawatan, Poltekkes Kemenkes Mataram, Indonesia; muhtarbima@gmail.com \\ (Corresponding Author) \\ ${ }^{2,3}$ Jurusan Keperawatan, Poltekkes Kemenkes Mataram, Indonesia
}

\begin{abstract}
Patient safety is an indicator of the quality of health service facilities, therefore the hospital always strives to improve the quality of service by providing safe and quality care and building a culture of patient safety even during crisis situations such as the Covid-19 pandemic. Aimed at knowing the description of the implementation of patient safety culture in RSUD Bima, this study used a descriptive observational design with a cross-sectional approach, respondents were taken by simple random sampling, data collection used the Hospital Survey on Patient Safety Culture (HSOPSC) questionnaire. In general, the implementation of patient safety culture in most dimensions has been perceived positively by more than $80 \%$ of respondents. Meanwhile, the lowest positive perception on the response dimension did not blame the error $(47.5 \%)$, staff management $(57.6 \%)$ and the frequency of reporting events / incidents $(58.5 \%)$. The investigators recommend continuing to improve the patient safety culture with special attention paid to the low mean dimensions to refine and strengthen these dimensions
\end{abstract}

Keywords: Patient safety culture; the covid-19 pandemic

\begin{abstract}
ABSTRAK
Keselamatan pasien merupakan indikator mutu sarana pelayanan kesehatan, oleh karena itu rumah sakit selalu berupaya meningkatkan mutu layanan melalui penyediaan perawatan yang aman dan berkualitas serta membangun budaya keselamatan pasien bahkan selama situasi krisis seperti masa pandemi Covid19. Bertujuan mengetahui gambaran pelaksanaan budaya keselamatan pasien di RSUD Bima penelitian ini menggunakan desain observasional deskriptif dengan pendekatan cross-sectional, responden diambil secara simple random sampling, pengumpulan data menggunakan kuesioner Hospital Survey on Patient Safety Culture (HSOPSC). Secara umum pelaksanaan budaya keselamatan pasien pada sebagian besar dimensi telah dipersepsikan positif oleh lebih dari $80 \%$ responden. Sementara persepsi positif terendah pada dimensi respon tidak menyalahkan terhadap kejadian kesalahan (47,5\%), pengaturan staf $(57,6 \%)$ dan frekuensi pelaporan kejadian/insiden (58,5\%). Peneliti merekomendasikan untuk terus meningkatakan budaya keselamatan pasien dengan perhatian khusus diberikan pada dimensi dengan ratarata rendah untuk memperbaiki dan memperkuat dimensi tersebut
\end{abstract}

Kata Kunci : budaya keselamatan pasien; pandemic covid-19

\section{PENDAHULUAN}

Keselamatan pasien merupakan komponen penting sebagai indikator mutu sarana pelayanan kesehatan (Chen \& Li, 2010). Sebuah Gerakan universal saat ini telah mempromosikan upaya 
peningkatan mutu pelayanan dan keselamatan pasien di rumah sakit, bahkan di berbagai negara maju telah merubah paradigma "quality" kepada paradigma baru "Quality-safety" yang tidak hanya berfokus pada peningkatan mutu pelayanan, namun menjaga keselamatan pasien secara konsisten dan terus menerus sebagai perioritas utama (Mandriani et al., 2019). Rumah sakit sebagai sebuah institusi pelayanan kesehatan mempunyai tujuan utama untuk menyelamatkan pasien yang merupakan prioritas bagi pelaksanaan lima isu penting tentang keselamatan di rumah sakit (Depkes RI, 2008), karena masalah keselamatan pasien berkaitan dengan kualitas dan citra institusi, maka rumah sakit selalu berupaya meningkatkan mutu layanan melalui penyediaan perawatan yang aman dan berkualitas serta membangun budaya keselamatan pasien bahkan selama situasi krisis seperti bencana alam, konflik, atau masa pandemi (Denning et al., 2020).

Pandemi Covid-19 merupakan kedaruratan kesehatan masyarakat, telah memberikan tekanan dan dampak yang besar pada dunia, termasuk Indonesia yang berpengaruh signifikan baik di bidang kesehatan maupun non-kesehatan. Pandemi Covid-19 ini tidak hanya meresahkan masyarakat atau pasien saja, tetapi memberikan beban yang signifikan pada sistem perawatan kesehatan, dengan konsekuensi perubahan drastis dalam cara pemberian perawatan kesehatan (Putri, 2020). Perubahan cepat dalam model pemberian perawatan terlihat selama pandemi Covid-19 termasuk peningkatan beban kerja, penempatan kembali staf ke lingkungan klinis yang tidak dikenal, pembatalan layanan rutin, dan persyaratan untuk merawat pasien baru (Denning et al., 2020).

Seiring dengan upaya institusi pelayanan kesehatan untuk meningkatkan kualitas perawatan mereka, semakin dikenal pentingnya membangun budaya keselamatan pasien. Budaya keselamatan mengacu pada sikap dan nilai manajerial dan pekerja yang terkait dengan manajemen risiko dan keselamatan keselamatan pasien. Pelaporan insiden merupakan aspek penting dari budaya keselamatan, sistem pelaporan tidak hanya mengukur kerusakan di tingkat organisasi, namun juga mengidentifikasi kerentanan sistem, mempromosikan pembelajaran, dan menunjukkan kesediaan staf untuk menyampaikan kekhawatiran (Gallego et al., 2012). Budaya keselamatan pasien juga dapat didefinisikan sebagai nilainilai yang dibagikan di antara staf rumah sakit tentang apa yang penting, keyakinan mereka tentang bagaimana hal-hal beroperasi dalam organisasi, dan interaksinya dengan unit kerja dan struktur dan sistem organisasi, yang bersama-sama menghasilkan norma perilaku dalam organisasi yang mempromosikan keselamatan (Dicuccio, 2015)

Tantangan terbesar dalam menciptakan budaya yang menjunjung keselamatan pasien adalah memulai, membiasakan dan mempertahankan budaya positif tentang keselamatan pasien pada organisasi pelayanan kesehatan (Syam, 2017). Bekerja dalam kondisi yang menantang seperti selama masa pandemic Covid-19 ini dapat berdampak pada kemampuan tenaga kesehatan untuk memberikan perawatan yang aman dan efektif. Penelitian sebelumnya telah mengidentifikasi keterbatasan organisasi, staf yang tidak memadai, peningkatan beban kerja dan kelelahan pemberi layanan sebagai kontributor untuk keselamatan pasien yang buruk (Jha et al., 2010). Dapat dibayangkan semua faktor ini mungkin telah ada selama pandemi, dan karena itu efek Covid-19 pada tenaga kerja dan dampaknya terhadap keselamatan pasien perlu diselidiki lebih lanjut. Satu cara untuk memperoleh wawasan tentang keadaan keselamatan pasien adalah melalui penilaian budaya keselamatan dan pelaporan insiden Insiden 
Keselamatan Pasien (IKP) yang terdiri dari Kejadian Tidak Diharapkan (KTD), Kejadian Nyaris Cedera (KNC), Kejadian Tidak Cedera (KTC) dan Kondisi Potensial Cedera (KPC) (Depkes RI, 2008). Sampai saat ini, belum ada evaluasi sistematis tentang dampak pandemi Covid-19 pada budaya keselamatan pasien. Oleh karena itu hasil penelitian ini diharapkan dapat menyajikan informasi tentang pelaksanaan budaya keselamatan pasien di Rumah Sakit Umum Daerah Bima.

\section{METODE}

Penelitian ini dilakukan di Rumah Sakit Umum Daerah Bima selama masa pandemic covid-19 yaitu pada bulan Mei sampai September 2020 dengan menerapkan protocol kesehatan, menggunakan desain observasional deskriptif dengan pendekatan cross-sectional, yang melibatkan 118 responden yang diambil secara simple random sampling dari berbagai jenis proefesi yang mewakili semua unit pelayanan yang ada di rumah sakit. Pengumpulan data menggunakan kuesioner HSOPSC yang dikembangkan oleh Agency for Healthcare Research and Quality sejak tahun 2004 (AHRQ, 2019), yang didesain untuk mengidentifikasi opini staf rumah sakit tentang isu keselamatan pasien, kesalahan medikasi, dan pelaporan kejadian. Kuesioner ini terdiri dari 42 item pertanyaan yang telah dilaksanakn uji validitas dan reliabilitas, meliputi 12 dimensi keselamatan pasien yang dikelompokkan kedalam kelompok outcome (hasil) 2 dimensi pertanyaan dan kelompok budaya keselamatan 10 dimensi pertanyaan.

\section{HASIL}

Tabel 1. Karakteristik Responden. di RSUD Bima tahun 2020

\begin{tabular}{|c|c|c|c|c|}
\hline No & Karakteristik Responden & $\mathbf{n}$ & $\%$ & p-value \\
\hline \multirow[t]{3}{*}{1} & Jenis Kelamin & & & \\
\hline & Laki-Laki & 33 & 27,97 & \\
\hline & Perempuan & 85 & 72,03 & \\
\hline \multirow[t]{5}{*}{2} & Umur & & & \\
\hline & Minimum & & & 25 \\
\hline & Maximum & & & 57 \\
\hline & Mean & & & 37,42 \\
\hline & Median & & & 35,5 \\
\hline \multirow[t]{4}{*}{3} & Tingkat Pendidikan & & & \\
\hline & SMA/SMK/MA & 28 & 23,73 & \\
\hline & Diploma & 56 & 47,46 & \\
\hline & Sarjana & 34 & 28,81 & \\
\hline \multirow[t]{7}{*}{4} & Lama Bekerja & & & \\
\hline & $<1$ tahun & 5 & 4,24 & \\
\hline & $1-5$ tahun & 20 & 16,95 & \\
\hline & 6-10tahun & 35 & 29,66 & \\
\hline & 11-15 tahun & 21 & 17,80 & \\
\hline & 16-20 tahun & 12 & 10,17 & \\
\hline & 21 tahun atau lebih & 25 & 21,19 & \\
\hline
\end{tabular}




\begin{tabular}{llccc}
\hline No & Karakteristik Responden & n & \% & p-value \\
\hline 5 & Profesi & 7 & 5,93 \\
& Dokter Spesialis & 14 & 11,86 \\
& Dokter Umum & 36 & 30,51 \\
& Perawat & 8 & 6,78 \\
& Bidan & 5 & 4,24 \\
& Penata Radiologi & 6 & 5,08 \\
& Analis Kesehatan & 3,39 \\
& Apoteker & 5 & 4,24 \\
& Rekam Medik & 5 & 7,63 \\
& Manajemen & 9 & 20,34 \\
& Lain-Lain & 24 & \\
6. Jumlah Jam Kerja & & 4,24 \\
& < 20 jam seminggu & 5 & 25,42 \\
& 20-39 jam seminggu & 30 & 70,34 \\
& 40 jam atau lebih seminggu & 83 & \\
\hline
\end{tabular}

Tabel 1 menunjukkan bahwa mayoritas responden berjenis kelamin perempuan dengan rentang umur antara 25 sampai 57 tahun, paling banyak berpendidikan diploma dengan lama bekerja di RSUD Bima paling banyak selama 6-10 tahun. Responden terbanyak berprofesi sebagai perawat dengan jam kerja terbanyak 40 jam atau lebih dalam seminggu.

Tabel 2. Persepsi budaya keselamatan pasien di RSUD Bima tahun 2020

\begin{tabular}{|c|c|c|c|c|}
\hline \multirow{3}{*}{ Dimensi Budaya Keselamatan Pasien } & \multicolumn{4}{|c|}{ Kategori Persepsi Responden } \\
\hline & \multicolumn{2}{|c|}{ Positif } & \multicolumn{2}{|c|}{ Negatif } \\
\hline & $\mathrm{n}$ & $\%$ & $\mathrm{n}$ & $\%$ \\
\hline \multicolumn{5}{|l|}{ Kelompok hasil (Outcome) } \\
\hline - Keseluruhan persepsi tentang keselamatan pasien & 85 & 72,0 & 33 & 28,0 \\
\hline - Frekuensi pelaporan kejadian/insiden & 69 & 58,5 & 49 & 41,5 \\
\hline \multicolumn{5}{|l|}{ Kelompok budaya keselamatan } \\
\hline Teamwork dalam unit & 113 & 95,8 & 5 & 4,2 \\
\hline $\begin{array}{l}\text { - Ekspektasi dan aksi pimpinan dalam mempromosikan } \\
\text { keselamatan pasien }\end{array}$ & 112 & 94,9 & 6 & 5,1 \\
\hline Proses belajar organisasi, perbaikan berkelanjutan & 110 & 93,2 & 8 & 6,8 \\
\hline $\begin{array}{l}\text { - Dukungan manajemen rumah sakit dalam keselamatan } \\
\text { pasien }\end{array}$ & 98 & 83,1 & 20 & 16,9 \\
\hline Umpan balik dan komunikasi kejadian kesalahan & 92 & 78,0 & 26 & 22,0 \\
\hline Keterbukaan komunikasi & 93 & 78,8 & 25 & 21,2 \\
\hline Teamwork antar unit dalam rumah sakit & 110 & 93,2 & 8 & 6,8 \\
\hline Staffing & 68 & 57,6 & 50 & 42,4 \\
\hline Handoffs (serah terima) dan transisi & 96 & 81,4 & 22 & 18,6 \\
\hline Respon tidak menyalahkan terhadap kejadian kesalahan & 56 & 47,5 & 62 & 52,5 \\
\hline
\end{tabular}


Table 2 menunjukan persepi responden terhadap pelaksanaan budaya keselamatan pasien mayoritas dalam kategori persepsi positif dengan persentase tertinggi pada dimensi team work dalam unit sebesar $95,8 \%$, semenatara 52,5\% responden memberikan persepsi negative pada dimensi respon tidak menyalahkan terhadap kejadian kesalahan.

\section{PEMBAHASAN}

Studi ini dilaksanakan selama masa pandemic Covid-19 dimana penerapan protokol yang menuntut kedisiplinan dan peran serta aktif tenaga kesehatan serta seluruh elemen masyarakat yang ada dilingkungan rumah sakit maupun diluar rumah sakit, untuk selalu menggunakan masker, mencuci tangan serta menjaga jarak dalam rangka saling melindungi satu sama lain dari penyebaran Covid-19. Disamping itu tenaga kesehatan dituntut untuk selalu mengutamakan keselamatan setiap berinteraksi dengan pasien, sehingga terbentuk budaya pelayanan yang mengutamakan keselamatan pasien (Pujilestari et al., 2014). Hasil penelitian secara umum pelaksanaan budaya keselamatan pasien menunjukan hasil yang positif. Pada sebagian besar dimensi budaya keselamatan pasien seperti teamwork dalam unit, ekspektasi dan aksi pimpinan dalam mempromosikan keselamatan pasien, proses belajar organisasi/perbaikan berkelanjutan, dukungan manajemen rumah sakit dalam keselamatan pasien, teamwork antar unit dalam rumah sakit, serta handoffs (serah terima) dan transisi telah dipersepsikan positif oleh lebih dari $80 \%$ responden. Sementara persepsi positif terendah pada dimensi respon tidak menyalahkan terhadap kejadian kesalahan (47,5\%), pengaturan staf $(57,6 \%)$, frekuensi pelaporan kejadian/insiden (58,5\%), dan keseluruhan persepsi tentang budaya keselamatan pasien $(72,0 \%)$.

Dalam studi ini, kami menggunakan HSOPSC untuk mengukur budaya keselamatan pasien yang melibatkan 118 responden yang dari semua unsur profesi kesehatan dan profesi penunjang di rumah sakit umum daerah Bima. Secara keseluruhan, rata-rata tingkat respon positif untuk 12 dimensi budaya keselamatan pasien dari survei HSOPSC adalah 77,83\%. Hasil penelitian menunjukkan bahwa staf rumah sakit umum daerah Bima merasa positif terhadap budaya keselamatan pasien di organisasinya. Dimensi yang mendapat tingkat respon positif tertinggi adalah "Kerja tim dalam unit", yang mirip dengan hasil yang dilaporkan di Belgia (Hellings et al., 2007) dan Belanda (Smits et al., 2008). Sedangkan dimensi yang memiliki persentase respon positif terendah adalah "Respon tidak menyalahkan terhadap kejadian kesalahan", artinya sebagian besar responden merasa masih ada budaya saling menyalahkan diantara sesama staf rumah sakit terhadap kejadian atau insiden keselamatan pasien yang dilaporkan. Persentase positif terendah berikutnya adala staffing yang berarti Sebagian besar responden merasa alokasi staf kurang memadai untuk menangani beban kerja terkait keselamatan pasien.

Persepsi positif tertinggi berturut-turut dimensi teamwork dalam unit, dimensi ekspektasi dan aksi pimpinan dalam mempromosikan keselamatan pasien, dimensi proses belajar organisasi dan perbaikan berkelanjutan, serta dimensi teamwork antar unit dalam rumah sakit. Hal ini menunjukan staf rumah sakit telah bekerja secara bersama-sama untuk mewujudkan pelayanan yang mengutamakan keselamatan pasien yang didasarkan pada keterbukaan komunikasi dan saling percaya sesama tim dalam satu unit 
pelayanan serta antar unit pelayanan dalam satu rumah sakit yang didukung pula oleh komintem pimpinan dalam mempromosikan pelayanan yang mengutakan keselamatan bagi pasien (Syam, 2017).

Persepti positif tinggi juga pada dimensi dukungan manajemen rumah sakit dalam keselamatan pasien mencerminkan keyakinan petugas layanan kesehatan tentang dedikasi kepemimpinan institusi terhadap keselamatan pasien, dukungan staf garis depan, dan penyampaian informasi tepat waktu tentang kebijakan yang memengaruhi pekerjaan mereka. Hampir semua unit rumah memberikan persepsi positif terhadap dukungan manajemen yang menunjukkan bahwa petugas layanan kesehatan menganggap manajemen secara khusus memperhatikan kesejahteraan mereka maupun kesejahteraan pasien. (Schwendimann et al., 2013). Hal ini sejalan dengan penelitian lainya bahwa dukunga manajemen untuk keselamatan pasian menjadi tantangan penting bagi semua pemangku kepentingan rumah sakit, meningkatkan budaya keselamatan rumah sakit diperlukan manajer rumah sakit yang sepenuhnya sadar dan berkomitmen untuk keselamatan pasien (Hellings et al., 2007).

\section{KESIMPULAN}

Persentase rata-rata keseluruhan tanggapan positif terhadap 12 dimensi budaya keselamatan adalah $77,83 \%$, skor tertinggi terkait dengan bidang "kerjasama tim di dalam unit" (95,8\%) dan skor terendah terkait dengan bidang "Respon tidak menyalahkan terhadap kejadian kesalahan" (47,5 \%) dan "Staffing" (57,6 \%). Meningkatkan budaya keselamatan pasien penting untuk meningkatkan indikator perawatan pasien. Selain itu, perhatian khusus harus diberikan pada dimensi dengan rata-rata rendah dalam studi ini untuk memperbaiki dan memperkuat dimensi tersebut.

\section{DAFTAR PUSTAKA}

AHRQ. (2019). Quality and Patient Safety Resources. https://www.ahrq.gov/patientsafety/resources/index.html

Chen, I. C., \& Li, H. H. (2010). Measuring patient safety culture in Taiwan using the Hospital Survey on Patient Safety Culture (HSOPSC). BMC Health Services Research, 10. https://doi.org/10.1186/1472-6963-10-152

Denning, M., Goh, E. T., Clarke, J., Almonte, M., Chidambaram, S., Przybylowicz, J., Sounderajah, V., Flott, K., Tan, B., Yalamanchili, S., Winter-Beatty, J., Scott, A., Martin, G., Markar, S., Wells, M., Purkayastha, S., \& Kinross, J. (2020). What Has Been the Impact of Covid-19 on Safety Culture? MedRxiv, 2020.06.15.20129080.

Depkes RI. (2008). Panduan Nasional Keselamatan Pasien Rumah Sakit (Patient Safety) (2nd ed.). Departemen Kesehatan RI.

Dicuccio, M. H. (2015). The Relationship between Patient Safety Culture and Patient Outcomes: A Systematic Review. Journal of Patient Safety, 11(3), 135-142. https://doi.org/10.1097/PTS.0000000000000058

Gallego, B., Westbrook, M. T., Dunn, A. G., \& Braithwaite, J. (2012). Investigating patient safety culture across a health system: Multilevel modelling of differences associated with service types and staff demographics. International Journal for Quality in Health Care, 24(4), 311-320. https://doi.org/10.1093/intqhc/mzs028 
Hellings, J., Schrooten, W., Klazinga, N., \& Vleugels, A. (2007). Challenging patient safety culture: Survey results. International Journal of Health Care Quality Assurance, 20(7), 620-632. https://doi.org/10.1108/09526860710822752

Jha, A. K., Prasopa-Plaizier, N., Larizgoitia, I., \& Bates, D. W. (2010). Patient safety research: An overview of the global evidence. Quality and Safety in Health Care, 19(1), 42-47. https://doi.org/10.1136/qshc.2008.029165

Mandriani, E., Hardisman, H., \& Yetti, H. (2019). Analisis Dimensi Budaya Keselamatan Pasien Oleh Petugas Kesehatan di RSUD dr Rasidin Padang Tahun 2018. Jurnal Kesehatan Andalas, 8(1), 131. https://doi.org/10.25077/jka.v8i1.981

Pujilestari, A., Maidin, A., \& Anggraeni, R. (2014). Budaya Keselamatan Pasien di Instalasi Rawat Inap RSUP Dr . Wahidin Sudirohusodo Kota Makassar. JURNAL MKMI, Maret 2014, Hal 57-64, 5764. https://doi.org/10.1109/TCOMM.2015.2456093

Putri, R. N. (2020). Indonesia dalam Menghadapi Pandemi Covid-19. Jurnal Ilmiah Universitas Batanghari Jambi, 20(2), 705. https://doi.org/10.33087/jiubj.v20i2.1010

Schwendimann, R., Zimmermann, N., Küng, K., Ausserhofer, D., \& Sexton, B. (2013). Variation in safety culture dimensions within and between US and Swiss hospital units: An exploratory study. BMJ Quality and Safety, 22(1), 32-41. https://doi.org/10.1136/bmjqs-2011-000446

Smits, M., Christiaans-Dingelhoff, I., Wagner, C., Wal, G. Van Der, \& Groenewegen, P. P. (2008). The psychometric properties of the "Hospital Survey on Patient Safety Culture" in Dutch hospitals. BMC Health Services Research, 8, 1-9. https://doi.org/10.1186/1472-6963-8-230

Syam, N. S. (2017). Implementasi Budaya Keselamatan Pasien oleh Perawat di Rumah Sakit Ibnu Sina Makassar. Kes Mas: Jurnal Fakultas Kesehatan Masyarakat, 11(2), 169-174. https://doi.org/10.12928/kesmas.v11i2.7140 